\title{
ACS Chemical Neuroscience Molecule Spotlight on Savella
}

\author{
Corey R. Hopkins*
}

Vanderbilt University, Vanderbilt University Medical Center Department of Pharmacology, and Vanderbilt Program in Drug Discovery, Nashville, Tennessee 37232-6600

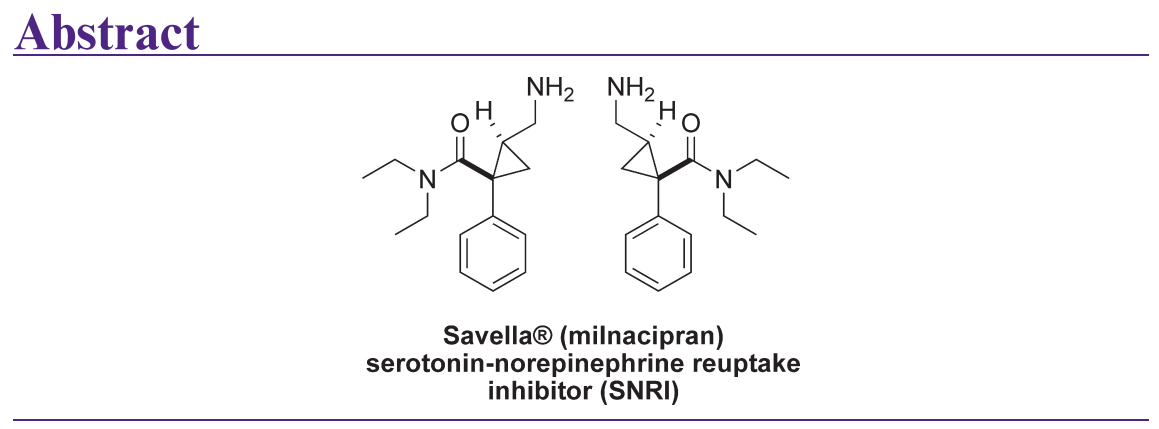

Savella (milnacipran), a selective serotonin and noradrenaline reuptake inhibitor, was approved by the FDA on January 14th, 2009, for the treatment of fibromyalgia.

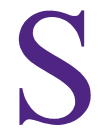
avella (milnacipran) is a recently approved psychoactive drug from Cypress Biosciences for the treatment of fibromyalgia (1). Fibromyalgia is a complex medical disorder characterized by chronic, widespread pain and allodynia (a heightened and painful response to pressure). This disorder is present is approximately $2 \%$ of the U.S. population and is much more likely to develop in women than in men; with the risk increasing with age (2). Although many cases of fibromyalgia develop after a physical or emotional trauma, in many other instances there appears to be no triggering event. People with fibromyalgia usually also have sleep disorders that prevent the individuals from reaching the deep, restorative stages of sleep. Due to this, many people also have other coexisting conditions, such as chronic fatigue syndrome, depression, and headaches, among others.

Savella (milnacipran) is an inhibitor of serotonin and norepinephrine reuptake in an approximate 3:1 ratio. In vitro, using radiolabeled serotonin and noradrenaline, milnacipran had potency against serotonin of $\mathrm{IC}_{50}=203 \mathrm{nM}$ and noradrenaline $\mathrm{IC}_{50}=100 \mathrm{nM}$ (3). In addition, milnacipran showed no activity for $\alpha$ - or $\beta$-adrenoceptors, muscarinics, histamine $\mathrm{H}_{1}$, dopamine $\mathrm{D}_{2}$, or serotonin 5- $\mathrm{HT}_{2}$ receptors (3). These results would suggest that milnacipran would be a useful and novel antidepressant drug; and in fact, it is. Milnacipran was first approved in France for the treatment of major depressive episodes in 1996 (marketed as Ixel). It is currently marketed for depression in over 45 countries, and in 2003, Cypress Biosciences purchased the exclusive rights for any purpose in the U.S. and Canada from Pierre Fabre.

The efficacy and ultimately the FDA approval were based on two pivotal clinical trials in the U.S. These studies showed that Savella (100 and $200 \mathrm{mg} /$ day) demonstrated clinically significant improvements compared with placebo in treating fibromyalgia. A larger number of Savella-treated patients experienced at least a $30 \%$ reduction in pain from baseline as well meeting the criteria for a treatment response as measured by improvements in pain, physical function, and patient global assessment $(4,5)$.

Savella (milnacipran) joins the ranks of Lyrica and Cymbalta as FDA-approved treatments of fibromyalgia and will give clinicians another treatment option for this disease.

\section{References}

1. Forest Laboratories, Inc. press release, Jan. 14th, 2009. http://www. frx.com $/$ news $/$ PressRelease.aspx?ID = 1244788

2. http://www.mayoclinic.com/health/ fibromyalgia/DS00079

3. Moret, C., Charveron, M., Finberg, J. P. M., Couzinier, J. P., and Briley, M. (1985) Biochemical profile of midalcipran (F 2207), 1-phenyl-1-diethyl-aminocarbonyl-2-aminomethyl-cyclopropane $(Z)$ hydrochloride, a potential fourth generation antidepressant drug. Neuropharmacology 24, 1211-1219.

4. Clauw, D. J., Mease, P., Palmer, R. H., Gendreau, R. M., and Wang, Y. (2008) Milnacipran for the treatment of fibromyalgia in adults: A 15-week, multicenter, randomized, double-blind, placebo-controlled, multiple-dose clinical trial. Clin. Ther. 30, 1988-2004.

5. Mease, P. J., Clauw, D. J., Gendreau, R. M., Rao, S. G., Kranzler, J., Chen, W., and Palmer, R. H. (2009) The efficacy and safety of milnacipran for treatment of fibromyalgia. A randomized, double-blind, placebo-controlled study. J. Rheumatol. 36, 398-409.

Received Date: March 8, 2010

Accepted Date: March 9, 2010

Published on Web Date: May 19, 2010 